\title{
EFEITOS DA APLICAÇÃO DE EFLUENTE DE TRATAMENTO DE ESGOTO NA FERTILIDADE DO SOLO E PRODUTIVIDADE DE PEPINO SOB IRRIGAÇÃO SUBSUPERFICIAL ${ }^{1}$
}

\author{
LEONARDO P. DE AZEVEDO ${ }^{2}$, EDUARDO L. DE OLIVEIRA ${ }^{3}$
}

RESUMO: O experimento foi conduzido com o objetivo de avaliar técnicas para a aplicação de águas residuárias na agricultura, proporcionando melhor reutilização de água, recurso natural atualmente escasso e muito mal disponibilizado. Utilizou-se da cultura de pepino (Cucumis sativus L.) em estufa, com oito parcelas irrigadas com efluentes de tratamento de esgoto residencial e oito parcelas irrigadas com água tratada e distribuída pela SABESP (tratamento-testemunha), ambas abastecidas por sistema de irrigação subsuperficial, avaliando-se a produção média por planta, a fertilidade do solo e a disposição de nutrientes na água do solo. Nas análises do solo, verificaram-se maiores teores de $\mathrm{P}, \mathrm{K} \mathrm{e}$ CTC no solo irrigado com efluentes. Nesse mesmo tratamento, constataram-se os maiores teores de N, nitrato, $\mathrm{Ca}, \mathrm{Mg}, \mathrm{Zn}$ e $\mathrm{S}$ para as análises da água retida na matriz do solo. Quanto à produção total média por planta, as parcelas irrigadas com efluente apresentaram $2.769,6 \mathrm{~g}$ de matéria fresca, superior aos 1.968,6 g verificados no tratamento-testemunha, demonstrando a importância da utilização de efluente de esgoto para o fornecimento de nutrientes e aumento de produtividade.

PALAVRAS-CHAVE: águas residuárias, irrigação localizada, Cucumis sativus L.

\section{APPLICATION EFFECTS OF SEWAGE TREATMENT EFFLUENT ON SOIL FERTILITY AND YIELD OF CUCUMBER WITH SUBSURFACE IRRIGATION}

\begin{abstract}
The objective of this work was to develop techniques to apply wasted water in agriculture, providing a better reuse of water, a natural resource which is scarce and very bad avaliable. Cucumber (Cucumis sativus L.) crop was used inside a greenhouse, with plots irrigated with treated water and plots irrigated with reclaimed water from residential sewage treatment, fed by a subsurface irrigation system, in order to assess the average production, soil fertility and water soil nutrient arrangement. In the soil basic analyse, increased levels of P, K and CTC were detected in the effluent irrigated soil. This same treatment demonstrated increased levels of $\mathrm{N}$, nitrate, $\mathrm{Ca}, \mathrm{Mg}, \mathrm{Zn}$ and $\mathrm{S}$ for water soil analyse. In the average production per plant, the irrigated treatment by effluent water showed values of $2,769.6 \mathrm{~g}$, higher than the values of $1,968.6 \mathrm{~g}$ which were verified in the treated water irrigated treatment, which demonstrates how important these techniques are for nutrient supply and productivity increase.
\end{abstract}

KEYWORDS: wasted water, localized irrigation, Cucumis sativus $\mathrm{L}$.

\section{INTRODUÇÃO}

A água constitui-se no recurso natural mais importante para o desenvolvimento da agricultura no mundo, uma vez que as novas tecnologias para aumento de produtividade das áreas agrícolas são dependentes da sua disponibilidade. Tal importância reflete-se nos altos índices de produtividade de áreas irrigadas, em que apenas $18 \%$ do total de áreas agrícolas correspondem a aproximadamente $40 \%$ da produção agrícola mundial (BROWN et al., 2000).

\footnotetext{
${ }^{1}$ Projeto de iniciação científica, financiado pela FAPESP.

${ }^{2}$ Eng $^{\mathrm{o}} \mathrm{Agr}^{\mathrm{o}}$, Mestrando, Departamento de Engenharia Rural, UNESP, Botucatu - SP, Fone: (0XX14) 6802.7165, pretto@ fca.unesp.br

${ }^{3}$ Eng ${ }^{\circ}$ Civil, Prof. Dr., Departamento de Engenharia Civil, UNESP, Bauru - SP, Fone: (0XX14) 221.6112, eduoliv@ feb.unesp.br

Recebido pelo Conselho Editorial em: 21-5-2003

Aprovado pelo Conselho Editorial em: 22-3-2005
}

Eng. Agríc., Jaboticabal, v.25, n.1, p.253-263, jan./abr. 2005 
Apesar de sua importância, esse recurso apresenta-se cada vez mais escasso, representando um problema ambiental de solução complexa (FAO, 1992).

A necessidade de desenvolvimento de técnicas para reutilização de água torna-se evidente quando avaliada a deficiente infra-estrutura sanitária existente no mundo, principalmente nos países em desenvolvimento. Segundo LÉON \& CAVALLINI (1999), estima-se que apenas 49\% da população da América Latina seja beneficiada com redes de esgoto, despejando diariamente cerca de 40 milhões de metros cúbicos de águas residuárias em rios, lagos ou mares, causando impacto ecológico, social e econômico.

A aplicação de esgoto no solo constitui uma das formas mais antigas de disposição final de esgotos sanitários (MARA \& CAIRNCROSS, 1989). Surgiu como forma de tratamento de esgoto, mas despertou o interesse de agricultores para sua aplicação na agricultura. Durante anos, essa prática tornou-se desaconselhável devido à presença de patógenos e preocupação com a saúde pública; no entanto, os problemas de escassez de água e o aumento das pesquisas sobre técnicas de aplicação segura e controlada de águas residuárias na agricultura fizeram ressurgir o interesse pelo assunto.

Segundo SWARTZ (1999), verifica-se na região da Flórida, Estados Unidos, a presença de 451 instalações de tratamento de esgoto, fornecendo diariamente cerca de 3,3 milhões de metros cúbicos de água reciclada para irrigação de gramados, parques e campos de golfe. Segundo PAPADOPOULOS \& STYLIANOU (1988), a aplicação de efluentes de tratamento de esgoto municipal em algodão, via irrigação por gotejo, deve ser considerada uma alternativa para fontes de água e nutrientes na agricultura, destacando-se o aumento dos níveis de nitrogênio do solo.

No entanto, deve-se levar em consideração que tais efluentes, em sua grande maioria, apresentam-se contaminados por microorganismos causadores de doenças em seres humanos, animais e algumas espécies de plantas e, portanto, devem ser utilizados com critérios.

Vale destacar que a escolha do método de aplicação de águas residuárias, bem como o tipo de cultura e manejo utilizados podem exercer papel fundamental na qualidade microbiológica final dos alimentos produzidos (EL-HAMOURI et al., 1996). BATARSEH et al. (1989) compararam a aplicação de efluentes de tratamento de esgoto hospitalar em três culturas, irrigadas por sulcos e gotejo. Para todas as situações, a contaminação bacteriológica foi superior na irrigação por sulcos, comprovando a importância da escolha de um sistema adequado. Em pesquisa realizada por ORON et al. (1991), também se observaram menores níveis de contaminação da cultura em irrigações realizadas por gotejo subsuperficial em relação ao sistema de microaspersão. Dessa forma, adotou-se o sistema de gotejo superficial na tentativa de minimizar contaminações da cultura.

Segundo DONEEN \& WESTCOT (1988), o sistema de irrigação localizada por gotejamento subsuperficial caracteriza-se por estar situado abaixo da superfície do solo, onde a água atinge a região radicular por ascensão capilar. Trata-se de um sistema recomendado para terrenos planos e que apresenta eficiência de aplicação de 50-70\%. Segundo PHENE et al. (1987), o sistema pode ser definido como a aplicação uniforme de pequenas quantidades de água, em intervalos freqüentes, abaixo da superfície do solo, pela emissão em pontos discretos ou em linha.

Quanto à escolha da cultura, plantas desenvolvidas rente ao solo estariam mais sujeitas a contaminação por microorganismos presentes no efluente de irrigação (MELLOUL et al., 2001). Aliada à escolha do sistema de irrigação, adotou-se a cultura do pepino (Cucumis sativus L.) devido sua importância econômica e por não se tratar de uma cultura rasteira, dificultando ainda mais as possibilidades de contaminação dos frutos.

Dessa maneira, o objetivo deste trabalho foi avaliar efeitos da aplicação de efluentes de tratamento de esgoto residencial em pepino (Cucumis sativus L.), quanto à fertilidade do solo, nutrientes da água do solo e produtividade da cultura. 


\section{MATERIAL E MÉTODOS}

\section{Caracterização do experimento}

O experimento foi conduzido na Fazenda Experimental Lageado, da Faculdade de Ciências Agronômicas da UNESP, Botucatu. Utilizou-se de um sistema de irrigação subsuperficial, no qual efluentes de tratamento de esgoto foram aplicados na cultura de pepino (Cucumis sativus L.). Tais efluentes foram originados de pesquisa desenvolvida no mesmo Câmpus por LEOPOLDO (1999).

Segundo ARANTES (2002), dados preliminares mostraram que a água resultante dessa pesquisa apresentou alto índice de coliformes totais e fecais, excedendo o limite passível de análise de 2.419,2 NMP $100 \mathrm{~mL}^{-1}$, de setembro ao final de dezembro de 2000. O índice de sólidos em suspensão encontrou-se abaixo do limite aceitável para irrigação por gotejamento, ou seja, inferior a $100 \mathrm{mg} \mathrm{L}^{-1}$, como proposto por ABREU et al. (1987).

Dessa forma, os efluentes foram direcionados para irrigar oito parcelas, via irrigação subsuperficial, na cultura do pepino. Foram irrigadas pelo mesmo processo mais oito parcelas com água tratada e distribuída pela SABESP, utilizadas como controle (tratamento testemunha). A localização das parcelas foi determinada por sorteio.

\section{Plantio e condução da cultura}

A condução do experimento em campo foi realizada de maio a novembro de 2000. O pepino foi semeado em bandejas de poliestireno expandido, em substrato comercial Plantimax - HT, no viveiro de mudas da Fazenda Experimental Lageado. Optou-se por sementes de pepino tipo japonês, da cultivar Hokuhoo Ky, importadas pela empresa AGROFLORA. As plântulas foram selecionadas e transplantadas para os canteiros, após o solo ter sido corrigido e adubado.

$\mathrm{Na}$ condução da cultura, esteve-se atento a basicamente dois fatores: o tutoramento por espaldadeira dupla e fio vertical, e a eliminação de brotações laterais, flores e frutos até a sexta folha definitiva, indispensáveis para que seu cultivo em estufa não se torne antieconômico.

Utilizou-se do delineamento em blocos casualizados, com oito repetições. Quatro linhas de plantio foram instaladas, na direção longitudinal da casa de vegetação, sendo cada linha subdividida em quatro canteiros de 4,50 $\mathrm{m}$ de comprimento por $0,50 \mathrm{~m}$ de largura e $0,40 \mathrm{~m}$ de profundidade.

Portanto, foram plantados 16 canteiros, oito irrigados com efluente e oito com água fornecida pela SABESP, cada canteiro contendo oito plantas, num total de 128 plantas transplantadas, como observado na Figura 1.

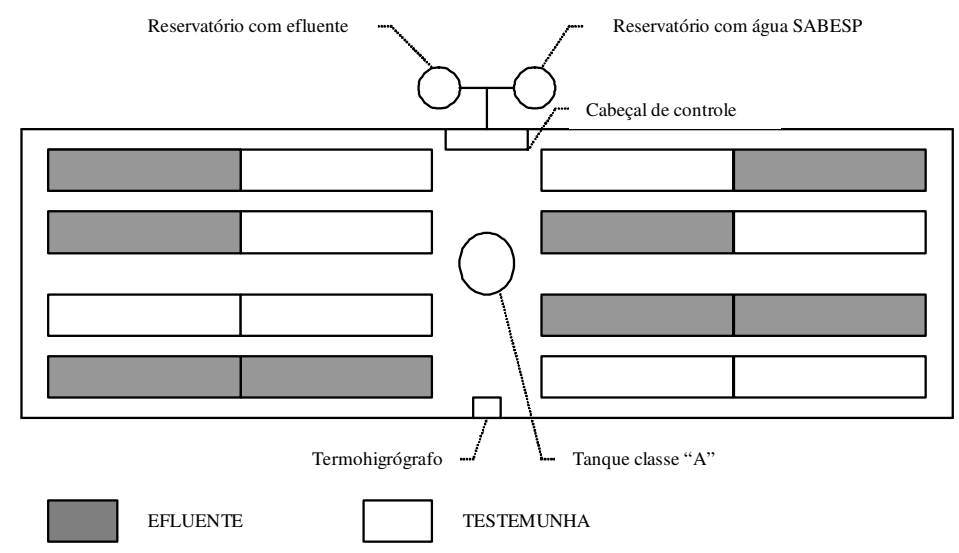

FIGURA 1. Caracterização da área experimental. 


\section{Sistema de irrigação}

Adotou-se o sistema de irrigação subsuperficial desenvolvido por OLIVEIRA (1997), utilizandose de tubos de plástico reciclável (polietileno) com diâmetro de $20 \mathrm{~mm}(3 / 4 ")$, enterrados a $20 \mathrm{~cm}$ de profundidade, e gotejadores de bambu, espaçados de $0,55 \mathrm{~m}$. O sistema trabalha com pouca pressão (1 a 2 mca), não exigindo sistema de bombeamento. Outro ponto a ser destacado é o diâmetro do furo no gotejador, que é de $1 \mathrm{~mm}$, e não apresentou sinais de entupimento durante os testes. Ainda assim, considerou-se necessária a colocação de um filtro de tela de 120 mesh para minimizar os entupimentos causados por partículas grosseiras que, por ventura, pudessem estar presentes após a saída do efluente do sistema de tratamento de esgoto por leitos cultivados.

\section{Monitoramento e manejo da irrigação}

O sistema de irrigação foi monitorado pela avaliação da evapotranspiração no interior da estufa, por meio de um tanque Classe A. Os dados de evapotranspiração de referência média para o período do experimento (Eto $=5,8 \mathrm{~mm} \mathrm{dia}^{-1}$ ), necessários para a determinação do coeficiente de cultivo da cultura nos estádios iniciais, foram obtidos junto ao Departamento de Recursos Naturais da FCA. Utilizou-se do coeficiente de tanque $\mathrm{Kp}=0,80$, segundo DOORENBOS \& PRUIT (1975), e turno de rega de dois dias.

Para a determinação do coeficiente de cultivo, adotaram-se quatro fases de desenvolvimento da planta, ainda segundo DOORENBOS \& PRUIT (1975): fase I (0-25 dias), Kc = 0,86; fase II (26-55 dias), $\mathrm{Kc}=0$,86; fase III (56-100 dias), $\mathrm{Kc}=0$,90, e fase IV (101-115 dias), $\mathrm{Kc}=0,70$.

Dessa maneira, determinou-se a lâmina de água necessária para a reposição da água evapotranspirada no dia anterior. O controle da lâmina aplicada foi realizado por meio de um hidrômetro, instalado no cabeçal de controle.

\section{Coletas de água do solo}

Coletaram-se amostras da água retida na matriz do solo para sua caracterização, com o auxílio de 32 extratores, duas em cada parcela, com a cápsula de cerâmica à profundidade de aproximadamente $40 \mathrm{~cm}$.

Tais amostras, coletadas nos dias 7 de agosto, 5 de setembro e 27 de novembro de 2000 (denominadas por épocas 1; 2 e 3, respectivamente), foram encaminhadas para análise de nutrientes (análise básica $+\mathrm{Al}+\mathrm{S}$ ) no Departamento de Recursos Naturais, da FCA-UNESP, Botucatu, e análise das concentrações de nitrato, nitrito e nitrogênio amoniacal no Laboratório de Águas Residuárias do Departamento de Engenharia Civil da UNESP, Bauru. A análise de nutrientes foi realizada pelo processo de espectrofotometria, à exceção do nitrogênio, o qual foi determinado por destilador de nitrogênio. Adotou-se a metodologia descrita por MALAVOLTA et al. (1997). Já as concentrações de nitrato, nitrito e nitrogênio amoniacal foram determinadas pelo processo de colorimetria, seguindo orientações descritas em GREENBERG et al. (1992).

\section{Coletas de solo}

No início do experimento, coletou-se uma amostra do solo utilizada para sua caracterização e devida correção. Durante o ciclo da cultura, efetuaram-se novas coletas para a verificação dos teores de nutrientes (análise básica $+\mathrm{Al}+\mathrm{S}$ ) do solo irrigado com efluente de esgoto tratado, em comparação ao solo do tratamento-testemunha. As amostras foram coletadas com o auxílio de um trado, à profundidade de $25 \mathrm{~cm}$, nos dias 16 de junho, 12 de setembro, 3 de outubro, 27 de outubro e 15 de dezembro de 2000.

\section{Coletas de frutos}

Durante o experimento, foram realizadas 12 colheitas consecutivas. Todos os frutos foram colhidos e imediatamente pesados para a determinação de produtividade de ambos os tratamentos. 
Com a constatação de pequenos problemas fitossanitários e até mesmo pela própria fisiologia da planta, nem todos os indivíduos da cultura tornaram-se produtivos. Portanto, para a determinação da produção média por planta em cada tratamento, somaram-se os valores de peso dos frutos e dividiu-se pelo número de plantas produtivas, tanto no tratamento com efluentes de esgoto como no tratamentotestemunha.

\section{Análise estatística}

Utilizou-se do delineamento em blocos casualizados, com oito repetições. Os dados obtidos foram submetidos à análise de variância e as médias comparadas pelo teste de Tukey, a 5\% .

\section{RESULTADOS E DISCUSSÃO}

Durante a pesquisa, coletaram-se amostras de solo para análise básica de nutrientes. Os intervalos de coleta foram denominados de $1^{\underline{a}}$ a $4^{\underline{a}}$ épocas, respectivamente, para os dias 12 de setembro, 3 de outubro, 27 de outubro e 15 de dezembro de 2000.

De maneira geral, não se observaram diferenças agronomicamente relevantes entre os solos dos dois tratamentos. Os teores de cálcio e magnésio, bem como os valores de $\mathrm{pH}$, soma de bases e V\% não diferiram entre si durante todo o período avaliado.

O teor de $\mathrm{H}+\mathrm{Al}$ (Tabela 1) e o valor de CTC do solo (Tabela 2) apresentaram diferenças na primeira e quarta épocas, em que o solo irrigado com efluentes apresentou maiores valores dessas variáveis.

Nas duas épocas intermediárias, constataram-se também valores mais elevados dessas variáveis no tratamento com efluente. No entanto, tal diferença não foi estatisticamente significativa.

$\mathrm{Na}$ terceira época, observou-se maior teor de matéria orgânica no solo irrigado por efluentes, valores esses que se inverteram para a época seguinte, como se observa na Tabela 3.

TABELA 1. Teores de hidrogênio + alumínio, em quatro épocas de amostragem, em função do tipo de água de irrigação utilizada.

\begin{tabular}{lcccc}
\hline \multirow{2}{*}{ Tratamentos } & \multicolumn{4}{c}{$\mathrm{H}+\mathrm{Al}$} \\
\cline { 2 - 5 } & $1^{\underline{\mathrm{a}}}$ Época & $2^{\text {a }}$ Época & $3^{\mathrm{a}}$ Época & $4^{\mathrm{a}}$ Época \\
\hline Testemunha & $40,25 \mathrm{~b}$ & $50,75 \mathrm{a}$ & $39,75 \mathrm{a}$ & $33,25 \mathrm{~b}$ \\
Efluente & $46,00 \mathrm{a}$ & $52,50 \mathrm{a}$ & $42,50 \mathrm{a}$ & $40,75 \mathrm{a}$ \\
Valor de F & $5,62 *$ & $0,45 \mathrm{~ns}$ & $0,79 \mathrm{~ns}$ & $9,29 * *$ \\
C.V. $(\%)$ & 11,3 & 10,1 & 15,1 & 13,3 \\
\hline
\end{tabular}

Médias seguidas de letras iguais na vertical não diferem estatisticamente, pelo teste Tukey, a 5\%.

**, * e ns - significativo a $1 \%$, a $5 \%$ e não significativo, respectivamente.

TABELA 2. Valores de capacidade de troca catiônica, em quatro épocas de amostragem, em função do tipo de água de irrigação utilizada.

\begin{tabular}{lcccc}
\hline \multirow{2}{*}{ Tratamentos } & \multicolumn{3}{c}{ CTC } \\
\cline { 2 - 5 } & $1^{\text {a }}$ Época & $2^{\text {a }}$ Época & $3^{\text {a }}$ Época & $4^{\text {a }}$ Época \\
\hline Testemunha & $88,50 \mathrm{~b}$ & $93,00 \mathrm{a}$ & $80,50 \mathrm{a}$ & $75,75 \mathrm{~b}$ \\
Efluente & $96,50 \mathrm{a}$ & $102,00 \mathrm{a}$ & $86,00 \mathrm{a}$ & $81,00 \mathrm{a}$ \\
Valor de F & $10,67 * *$ & $3,86 \mathrm{~ns}$ & $4,26 \mathrm{~ns}$ & $52,32 * *$ \\
C.V. $(\%)$ & 5,3 & 9,4 & 6,4 & 1,9 \\
\hline
\end{tabular}

Médias seguidas de letras iguais na vertical não diferem estatisticamente, pelo teste Tukey, a $5 \%$.

** e ns - significativo a $1 \%$ e não significativo, respectivamente. 
TABELA 3. Teores de matéria orgânica, em quatro épocas de amostragem, em função do tipo de água de irrigação utilizada.

\begin{tabular}{lcccc}
\hline \multirow{2}{*}{ Tratamentos } & \multicolumn{4}{c}{ Matéria Orgânica } \\
\cline { 2 - 5 } & $1^{\text {a }}$ Época & $2^{\text {a }}$ Época & $3^{\text {a }}$ Época & $4^{\text {a }}$ Época \\
\hline Testemunha & $22,00 \mathrm{a}$ & $21,50 \mathrm{a}$ & $18,50 \mathrm{~b}$ & $20,75 \mathrm{a}$ \\
Efluente & $21,75 \mathrm{a}$ & $21,50 \mathrm{a}$ & $20,50 \mathrm{a}$ & $19,75 \mathrm{~b}$ \\
Valor de F & $0,16 \mathrm{~ns}$ & $0,00 \mathrm{~ns}$ & $56,00 * *$ & $8,00 *$ \\
C.V. $(\%)$ & 5,67 & 6,1 & 2,7 & 3,5 \\
\hline
\end{tabular}

Médias seguidas de letras iguais na vertical não diferem estatisticamente, pelo teste Tukey, a 5\%.

**, * e ns - significativo a $1 \%$, a $5 \%$ e não significativo, respectivamente.

Essa descontinuidade nos resultados obtidos pode ter refletido a variação da composição química do efluente utilizado, pois se trata de efluente originário do tratamento de esgoto residencial, diretamente dependente do hábito dos moradores durante o período da pesquisa.

Observou-se ainda, no tratamento por água residuária, elevação nos teores de fósforo (Tabela 4) na terceira e quarta épocas, e no teor de potássio (Tabela 5) apenas na quarta época.

TABELA 4. Teores de fósforo, em quatro épocas de amostragem, em função do tipo de água de irrigação utilizada.

\begin{tabular}{lcccl}
\hline \multirow{2}{*}{ Tratamentos } & \multicolumn{4}{c}{ Fósforo } \\
\cline { 2 - 5 } & $1^{\text {a }}$ Época & $2^{\text {a }}$ Época & $3^{\text {a }}$ Época & $4^{\text {a }}$ Época \\
\hline Testemunha & $57,50 \mathrm{a}$ & $54,75 \mathrm{a}$ & $37,50 \mathrm{~b}$ & $48,25 \mathrm{~b}$ \\
Efluente & $47,50 \mathrm{a}$ & $47,50 \mathrm{a}$ & $60,25 \mathrm{a}$ & $77,50 \mathrm{a}$ \\
Valor de F & $3,81 \mathrm{~ns}$ & $1,07 \mathrm{~ns}$ & $12,58 * *$ & $82,68 * *$ \\
C.V. $(\%)$ & 19,5 & 27,5 & 26,3 & 10,2
\end{tabular}

Médias seguidas de letras iguais na vertical não diferem estatisticamente, pelo teste Tukey, a $5 \%$.

** e ns - significativo a $1 \%$ e não significativo, respectivamente.

TABELA 5. Teores de potássio, em quatro épocas de amostragem, em função do tipo de água de irrigação utilizada.

\begin{tabular}{lcccc}
\hline \multirow{2}{*}{ Tratamentos } & \multicolumn{4}{c}{ Potássio } \\
\cline { 2 - 5 } & $1^{\underline{a}}$ Época & $2^{\text {a }}$ Época & $3^{\text {a }}$ Época & $4^{\text {a }}$ Época \\
\hline Testemunha & $2,40 \mathrm{a}$ & $2,08 \mathrm{a}$ & $1,73 \mathrm{a}$ & $1,40 \mathrm{~b}$ \\
Efluente & $2,50 \mathrm{a}$ & $1,90 \mathrm{a}$ & $1,48 \mathrm{a}$ & $1,78 \mathrm{a}$ \\
Valor de F & $0,14 \mathrm{~ns}$ & $2,00 \mathrm{~ns}$ & $2,10 \mathrm{~ns}$ & $7,46 *$ \\
C.V. $(\%)$ & 21,49 & 12,4 & 21,6 & 17,3
\end{tabular}

Médias seguidas de letras iguais na vertical não diferem estatisticamente, pelo teste Tukey, a 5\%.

* e ns - significativo a $5 \%$ e não significativo, respectivamente.

Nesses casos, pode ter ocorrido acúmulo gradual de fósforo e potássio no solo, detectado apenas no final do período avaliado. Seria interessante, para esses casos, que a avaliação fosse realizada por maior período para que se pudessem detectar os reais efeitos da aplicação de efluentes nesse solo.

Quanto aos nutrientes presentes na água retida na matriz do solo, foram coletadas amostras em 7 de agosto, 5 de setembro e 27 de novembro de 2000, estando os resultados das análises apresentados nas Tabelas 6 a 13.

Os teores de nitrogênio (Tabela 6) e nitrato (Tabela 7) foram estatisticamente mais elevados para o tratamento com efluente, na segunda e terceira amostragem. 
TABELA 6. Teores de nitrogênio, em três épocas de amostragem, em função do tipo de água de irrigação utilizada.

\begin{tabular}{lccc}
\hline \multirow{2}{*}{ Tratamentos } & \multicolumn{3}{c}{ Teores de Nitrogênio $\left(\mathrm{mg} \mathrm{L}^{-1}\right)$} \\
\cline { 2 - 4 } & Amostra 1 & Amostra 2 & Amostra 3 \\
\hline Testemunha & $75,00 \mathrm{a}$ & $50,50 \mathrm{~b}$ & $15,75 \mathrm{~b}$ \\
Efluente & $163,67 \mathrm{a}$ & $144,25 \mathrm{a}$ & $66,50 \mathrm{a}$ \\
Valor de F & $4,72 \mathrm{~ns}$ & $13,44 * *$ & $94,92 * *$ \\
C.V. $(\%)$ & 59,3 & 52,5 & 25,3 \\
\hline
\end{tabular}

Médias seguidas de letras iguais na vertical não diferem estatisticamente, pelo teste Tukey, a 5\%.

** e ns - significativo a $1 \%$ e não significativo, respectivamente.

TABELA 7. Teores de nitrato, em três épocas de amostragem, em função do tipo de água de irrigação utilizada.

\begin{tabular}{lccc}
\hline \multirow{2}{*}{ Tratamentos } & \multicolumn{3}{c}{ Teores de Nitrato $\left(\mathrm{N}-\mathrm{NO}_{3}\right)\left(\mathrm{mg} \mathrm{L}^{-1}\right)$} \\
\cline { 2 - 4 } & Amostra 1 & Amostra 2 & Amostra 3 \\
\hline Testemunha & $67,67 \mathrm{a}$ & $60,43 \mathrm{~b}$ & $23,50 \mathrm{~b}$ \\
Efluente & $76,33 \mathrm{a}$ & $123,13 \mathrm{a}$ & $54,00 \mathrm{a}$ \\
Valor de F & $0,22 \mathrm{~ns}$ & $12,90 * *$ & $54,61 * *$ \\
C.V. $(\%)$ & 44,8 & 38,0 & 21,3 \\
\hline ME & &
\end{tabular}

Médias seguidas de letras iguais na vertical não diferem estatisticamente, pelo teste Tukey, a 5\%.

** e ns - significativo a $1 \%$ e não significativo, respectivamente.

Para o mesmo tratamento, observou-se, ainda, aumento significativo no teor de nitrogênio amoniacal na segunda amostragem, apresentado na Tabela 8.

TABELA 8. Teores de nitrogênio amoniacal, em três épocas de amostragem, em função do tipo de água de irrigação utilizada.

\begin{tabular}{|c|c|c|c|}
\hline \multirow{2}{*}{ Tratamentos } & \multicolumn{3}{|c|}{ Teores de Nitrogênio Amoniacal $\left(\mathrm{N}-\mathrm{Nh}_{3}\right)\left(\mathrm{mg} \mathrm{L}^{-1}\right)$} \\
\hline & Amostra 1 & Amostra 2 & Amostra 3 \\
\hline Testemunha & $5,27 \mathrm{a}$ & $0,00 \mathrm{~b}$ & $0,23 \mathrm{a}$ \\
\hline Efluente & $4,83 \mathrm{a}$ & $0,48 \mathrm{a}$ & $0,13 \mathrm{a}$ \\
\hline Valor de F & $0,01 \mathrm{~ns}$ & $72,17 * *$ & $2,95 \mathrm{~ns}$ \\
\hline C.V. $(\%)$ & 149,0 & 47,1 & 66,5 \\
\hline
\end{tabular}

Médias seguidas de letras iguais na vertical não diferem estatisticamente, pelo teste Tukey, a 5\%.

** e ns - significativo a $1 \%$ e não significativo, respectivamente.

Para o nitrito, não se constataram diferenças significativas entre os dois tratamentos (efluente e água da SABESP), em nenhuma das amostragens consideradas.

Isso em vista, destaca-se que a absorção de nitrogênio pela raiz das plantas acontece, preferencialmente, na forma de nitrato, constatado em maior quantidade no tratamento por efluentes. $\mathrm{O}$ nitrogênio amoniacal (Tabela 8) e o nitrito são absorvidos em pequena quantidade, geralmente transformados em nitrato para posterior absorção. Dessa forma, tornam-se importantes os maiores teores de nitrogênio presente na água do solo tratado com efluentes, principalmente na forma de nitrato. Essa maior quantidade pode ter sido fundamental na maior produtividade das plantas nesse tratamento em relação ao tratamento-testemunha, como apresentado na Figura 2.

Em relação aos teores de fósforo encontrados na água do solo, não se observou diferença significativa entre os tratamentos durante o experimento. 
Quanto aos teores de potássio, cálcio e magnésio, observaram-se valores estatisticamente maiores desse nutriente na água do solo irrigado pelo efluente, para a segunda e terceira amostras, apresentados respectivamente nas Tabelas 9; 10 e 11. Nesses casos, pode ter ocorrido acúmulo desses nutrientes na água retida no solo, constatado a partir da segunda amostragem.

Quanto aos teores de enxofre (Tabela 12) e zinco (Tabela 13), observaram-se valores significativamente maiores em relação ao tratamento-testemunha, na última amostragem. Nesses casos, pode ter ocorrido comportamento semelhante ao citado para $\mathrm{K}, \mathrm{Ca}$ e $\mathrm{Mg}$, diferindo apenas no tempo transcorrido para que se detectassem os efeitos da irrigação com efluentes de esgoto.

TABELA 9. Teores de potássio, em três épocas de amostragem, em função do tipo de água de irrigação utilizada.

\begin{tabular}{lccc}
\hline \multirow{2}{*}{ Tratamentos } & \multicolumn{3}{c}{ Teores de Potássio $\left(\mathrm{mg} \mathrm{kg}^{-1}\right)$} \\
\cline { 2 - 4 } & Amostra 1 & Amostra 2 & Amostra 3 \\
\hline Testemunha & $35,00 \mathrm{a}$ & $23,25 \mathrm{~b}$ & $17,50 \mathrm{~b}$ \\
Efluente & $58,00 \mathrm{a}$ & $50,50 \mathrm{a}$ & $30,00 \mathrm{a}$ \\
Valor de F & $1,84 \mathrm{~ns}$ & $14,24 * *$ & $8,80 * *$ \\
C.V. $(\%)$ & 63,1 & 39,2 & 35,5 \\
\hline
\end{tabular}

Médias seguidas de letras iguais na vertical não diferem estatisticamente, pelo teste Tukey, a 5\%.

** e ns - significativo a $1 \%$ e não significativo, respectivamente.

TABELA 10. Teores de cálcio, em três épocas de amostragem, em função do tipo de água de irrigação utilizada.

\begin{tabular}{lccc}
\hline \multirow{2}{*}{ Tratamentos } & \multicolumn{3}{c}{ Teores de Cálcio $\left(\mathrm{mg} \mathrm{kg}^{-1}\right)$} \\
\cline { 2 - 4 } & Amostra 1 & Amostra 2 & Amostra 3 \\
\hline Testemunha & $119,00 \mathrm{a}$ & $103,75 \mathrm{~b}$ & $25,75 \mathrm{~b}$ \\
Efluente & $237,00 \mathrm{a}$ & $194,75 \mathrm{a}$ & $67,50 \mathrm{a}$ \\
Valor de F & $2,24 \mathrm{~ns}$ & $4,70 *$ & $15,90 * *$ \\
C.V. $(\%)$ & 76,7 & 56,2 & 44,9 \\
\hline
\end{tabular}

Médias seguidas de letras iguais na vertical não diferem estatisticamente, pelo teste Tukey, a 5\%.

**, * e ns - significativo a $1 \%$, a $5 \%$ e não significativo, respectivamente.

TABELA 11. Teores de magnésio, em três épocas de amostragem, em função do tipo de água de irrigação utilizada.

\begin{tabular}{lccc}
\hline \multirow{2}{*}{ Tratamentos } & \multicolumn{3}{c}{ Teores de Magnésio $\left(\mathrm{mg} \mathrm{kg}^{-1}\right)$} \\
\cline { 2 - 4 } & Amostra 1 & Amostra 2 & Amostra 3 \\
\hline Testemunha & $47,67 \mathrm{a}$ & $36,50 \mathrm{~b}$ & $10,75 \mathrm{~b}$ \\
Efluente & $91,67 \mathrm{a}$ & $73,75 \mathrm{a}$ & $28,5 \mathrm{a}$ \\
Valor de F & $2,27 \mathrm{~ns}$ & $4,94 *$ & $15,38 * *$ \\
C.V. $(\%)$ & 72,6 & 60,8 & 46,1 \\
\hline
\end{tabular}

Médias seguidas de letras iguais na vertical não diferem estatisticamente, pelo teste Tukey, a 5\%.

**, * e ns - significativo a $1 \%$, a $5 \%$ e não significativo, respectivamente. 
TABELA 12. Teores de enxofre, em três épocas de amostragem, em função do tipo de água de irrigação utilizada.

\begin{tabular}{lccc}
\hline \multirow{2}{*}{ Tratamentos } & \multicolumn{3}{c}{ Teores de Enxofre $\left(\mathrm{mg} \mathrm{kg}^{-1}\right)$} \\
\cline { 2 - 4 } & Amostra & Amostra 2 & Amostra 3 \\
\hline Testemunha & $47,67 \mathrm{a}$ & $73,75 \mathrm{a}$ & $25,00 \mathrm{~b}$ \\
Efluente & $89,67 \mathrm{a}$ & $80,00 \mathrm{a}$ & $65,50 \mathrm{a}$ \\
Valor de F & $2,13 \mathrm{~ns}$ & $0,14 \mathrm{~ns}$ & $5,22 *$ \\
C.V. $(\%)$ & 72,6 & 43,1 & 78,3 \\
\hline
\end{tabular}

Médias seguidas de letras iguais na vertical não diferem estatisticamente, pelo teste Tukey, a 5\%.

* e ns - significativo a $5 \%$ e não significativo, respectivamente.

TABELA 13. Teores de zinco, em três épocas de amostragem, em função do tipo de água de irrigação utilizada.

\begin{tabular}{lccc}
\hline \multirow{2}{*}{ Tratamentos } & \multicolumn{3}{c}{ Teores de Zinco $\left(\mathrm{mg} \mathrm{kg}^{-1}\right)$} \\
\cline { 2 - 4 } & Amostra & Amostra 2 & Amostra 3 \\
\hline Testemunha & $0,26 \mathrm{a}$ & $0,11 \mathrm{a}$ & $0,05 \mathrm{~b}$ \\
Efluente & $0,58 \mathrm{a}$ & $0,10 \mathrm{a}$ & $0,12 \mathrm{a}$ \\
Valor de F & $0,91 \mathrm{~ns}$ & $0,12 \mathrm{~ns}$ & $14,79 * *$ \\
C.V. $(\%)$ & 138,3 & 68,3 & 48,1 \\
\hline
\end{tabular}

Médias seguidas de letras iguais na vertical não diferem estatisticamente, pelo teste Tukey, a 5\%.

** e ns - significativo a $1 \%$ e não significativo, respectivamente.

Na Figura 2, mostra-se a produção média por planta nos dois tratamentos, da primeira à décima-segunda colheitas.

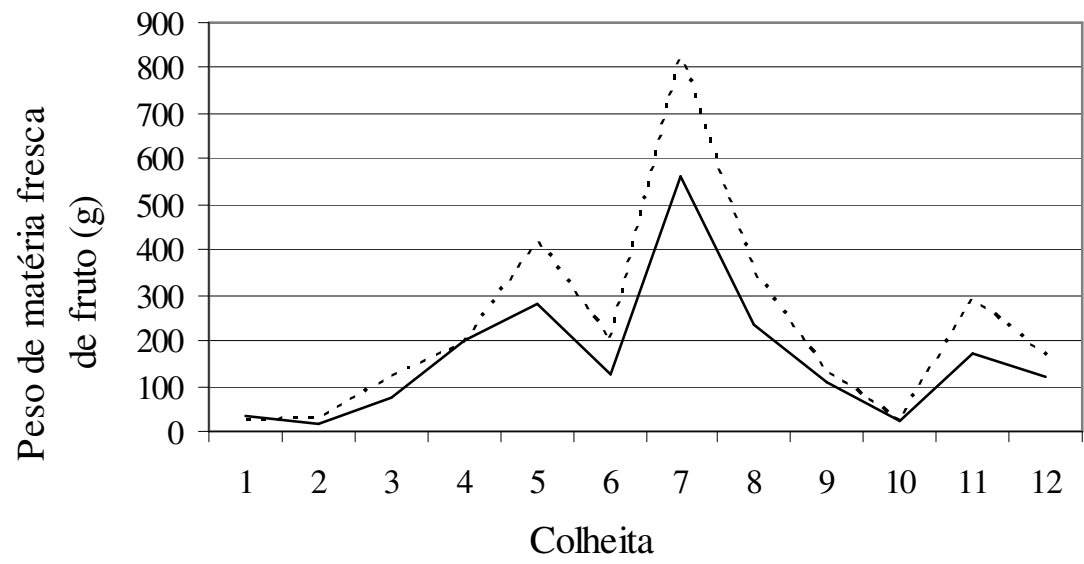

Testemunha $\cdot \cdots \cdot \cdot$. efluente de esgoto tratado

FIGURA 2. Produção média em gramas por planta durante as 12 colheitas realizadas, em função do tipo de água de irrigação utilizada.

De maneira geral, observam-se, com frequiência, maiores médias de produção no tratamento com efluente; ainda que, somente nas colheitas 3; 7 e 8, essas diferenças viessem a ser estatisticamente significativas.

Essas pequenas diferenças acumularam-se durante o período do experimento, resultando numa produção média total por planta estatisticamente muito superior no tratamento com água residuária, se comparada ao tratamento testemunha. 
A produção média total por planta foi de $1.968,6 \mathrm{~g}$ de peso fresco para o tratamento-testemunha e $2.769,7 \mathrm{~g}$ de peso fresco para a irrigação com efluente, ou seja, uma diferença de 40,7\%. Esses valores foram estatisticamente distintos, pelo teste de Tukey, a 5\%.

Vale destacar que a desuniformidade de produção por planta, observada entre uma colheita e outra nos tratamentos, refere-se à própria fisiologia da planta, dependente de fatores intrínsecos e extrínsecos que não se apresentam de forma homogênea, como idade da planta, condições climáticas e produção da colheita anterior.

Constataram-se, durante a pesquisa, valores mais elevados de certas variáveis no tratamento com efluente, que podem ter influenciado nos resultados de produção média total por planta. Dentre essas variáveis, destacam-se o P, K, e CTC no solo avaliado, bem como N, nitrogênio amoniacal, nitrato, K, $\mathrm{Ca}, \mathrm{Mg}, \mathrm{Zn}$ e $\mathrm{S}$ na água retida na matriz desse solo.

Os maiores valores dessas variáveis, ainda que não constatados durante todo o período da pesquisa, podem ter atuado de forma sinérgica na fisiologia da planta, sendo de fundamental importância para o aumento de produtividade constatado no tratamento com efluente de esgoto.

\section{CONCLUSÕES}

A irrigação com efluente contribuiu significativamente para o aumento no teor de $\mathrm{N}$, nitrogênio amoniacal, nitrato, $\mathrm{K}, \mathrm{Ca}, \mathrm{Mg}$, $\mathrm{Zn}$ e $\mathrm{S}$ retidos na solução do solo.

A irrigação subsuperficial com efluente de tratamento de esgoto contribuiu para o aumento de produção de plantas de pepino (Cucumis sativus L.), cultivar Hokuhoo Ky, conduzidos em estufa.

\section{REFERÊNCIAS}

ABREU, J.M.H.; LÓPEZ, J.R.; REGALADO, A.P.; HERNÁNDEZ, J.F.G. El riego localizado. In: CURSO INTERNACIONAL DE RIEGO LOCALIZADO. Tenerife: Instituto Nacional de Investigaciones Agrarias, 1987. 317 p.

ARANTES, L.A. Utilização de lagoas de maturação com aguapé (Eichhornia crassipes (Mart.) Solms) no tratamento terciário de efluente doméstico de uma comunidade rural. $2002.113 \mathrm{f}$. Dissertação (Mestrado em Energia na Agricultura) - Faculdade de Ciências Agronômicas, Universidade Estadual Paulista, Botucatu, 2002.

BATARSEH, L.I.; RUIRAWI, O.M.; SALAMEH, E. Treated wastewater reuse in agriculture. Hussein medical center project. Amman (Jordan): Water Research and Study Center, Jordan University, 1989. Part 1, 54 p.

BRASIL. Conselho Nacional do Meio Ambiente. Resolução CONAMA n⿳ํㅡㄹ 20 de 18 junho de 1986. Diário Oficial da União, Brasília, 30, julho, 1986.

BROWN, L.R.; RENNER, M.; HALWEIL, B. Sinais vitais 2000: as tendências ambientais que determinarão nosso futuro. Salvador: UMA, 2000. 196 p.

DONEEN, L.D.; WESTCOT, D.W. Irrigation practice and water management. Roma: FAO, 1988. 71 p. (Irrigation and Drainage, Paper 01)

DOOREMBOS, J.; PRUITT, W.O. Guidelines for predicting crop water requirements. Roma: FAO, 1975. $179 \mathrm{p}$.

El-HAMOURI, B.; HANDOUF, A.; MEKRANE, M.; TOUZANI, M. Use of wastewater for crop production under arid and saline conditions: yield and hygienic quality of the crop and soil contaminations. Water Science and Technology, Oxford, v.33, n.10-11, p.327-34, 1996. 
FAO. Wastewater treatment and use in agriculture. Roma, 1992. 125 p. (Irrigation and Drainage, Paper 47)

GREENBERG, A.E.; CLESCERI, L.S.; EATON; A.D. Standard methods for the examination of water and wastewater. $18^{\text {th }}$ ed. Washington: APHA, AWWA, WEF, 1992. Irregular pagination.

LÉON, G.S.; CAVALLINI, J.M. Tratamento e uso de águas residuárias. Campina Grande: Universidade Federal da Paraíba, 1999. 110 p.

LEOPOLDO, P.R.; GUIMARÃES, A.B.; BREDA, C.C. Tratamento de efluentes domésticos em zona rural através de sistema com plantas aquáticas. In: CONGRESSO BRASILEIRO DE ENGENHARIA AGRÍCOLA, 28., 1999, Pelotas. Anais...Pelotas: Sociedade Brasileira de Engenharia Agrícola, 1999. 1 CD ROM.

MALAVOLTA, E.; VITTI, G.C.; OLIVEIRA, S.A. Avaliação do estado nutricional das plantas: princípios e aplicações. 2.ed. Piracicaba: POTAFOS, 1997. 319 p.

MARA, D.; CAIRNCROSS, S. Guidelines for the safe use of wastewater and excreta in agriculture and aquaculture: Measures for public health protection. Geneva: World Health Organization, 1989. $187 \mathrm{p}$.

MELLOUL, A.AIT; HASSANI, L.; RAFOUK, L. Salmonella contamination of vegetables irrigated with untreated wastewater. World Journal of Microbiology and Biotechnology, Oxford, v.17, n.2, p.207-9, 2001.

OLIVEIRA, E.L. Gotejadores de bambu para utilização em sistemas de irrigação subsuperficial: uma solução para pequenos produtores. 1997. 113 f. Tese (Doutourado em Irrigação e Drenagem) Faculdade de Ciências Agronômicas, Universidade Estadual Paulista, Botucatu, 1997.

ORON, G. et al. Effluent reuse by trickle irrigation. Water Science and Technology, Oxford, v.24, n.9, p.103-8, 1991.

PAPADOPOULOS, I.; STYLIANOU, Y. Trikle irrigation of cotton with treated sewage effluent. Journal of Environmental Quality, Madison, v.17, n.4, p.574-80, 1988.

PHENE, C.J.; DAVIS, K.R.; HUTMACHER, R.B.; McCOMICK, R.L. Advantages of subsurface irrigation for processing tomatoes. Acta Agriculturae, Copenhagen, v.200, p.101-14, 1987.

SWARTZ, J.S. A computer water balance model for the evaluation of slow-rate land application systems in Florida. NET, jan. 1999. Disponível em: <http://www2.dep.state.fl.us/water/wf/dom/ landap98.htm>. Acesso em: 20 de jan. de 2000. 